\title{
Evaluation of mitochondria-organelle peptides versus nano-sized cellular extracts in aesthetic dermatology: comparative case study.
}

\author{
Dina Tukhvatullina, MD, cPhD, Stellar Biomolecular Research \\ Shing Yi Pan, PhD (Biotech), M.Biotech, BBiomedSc., Stellar Biomolecular Research
}

Comparative case study aimed to analyze efficacy of two peptide formulas: F1 with molecular weight 1-10 kDa and F2: combination of $1-10 \mathrm{kDa}$ with $45-65 \mathrm{kDa}$.

Method. Twice a week injections performed 6 weeks on 10 volunteers for each formula spending $2 \mathrm{ml}$ per session on upper face (in each injection, approximately $0.01 \mathrm{ml}$ of formula was injected into the skin at a depth of $2 \mathrm{~mm}$ using the papule technique following the wrinkles direction). The clinical status of the skin in terms of wrinkles, tautness, and texture was evaluated and rated by the volunteer, two dermatologists, and two independent observers before treatment, at the end and third months after the start of treatment. Rating was based on a 5 -point scale on which improvement was rated as none $(0 \%)$, mild (1-25\%), moderate (26-50\%), good (51-75\%), or very $\operatorname{good}(76-100 \%)$

Results. All 20 volunteers completed protocol and showed improvement $45-50 \%$ on $\mathrm{F} 1$ and $60-75 \%$ on $\mathrm{F} 2$ in skin tightening and texture at end of treatment vs $35-45 \%$ and $50-$ $60 \%$ at 3 months later respectively. Clinical improvement of wrinkles ranged from good to moderate in F1 and good in F-2. Starting from week 3 evaluations showed a statistically and clinically significant reduction of profilometric parameters vs baseline on average roughness and total wrinkle height. The effect of treatment on collagen types I and III was measured as percentage of the dermis occupied by immunohistochemically detectable collagen and compared these values with measurements obtained at baseline (by immunoperoxidase staining). Newly synthesized collagen was evaluated by picrosirius red staining.

\section{Skin parameters improvement (\%)}

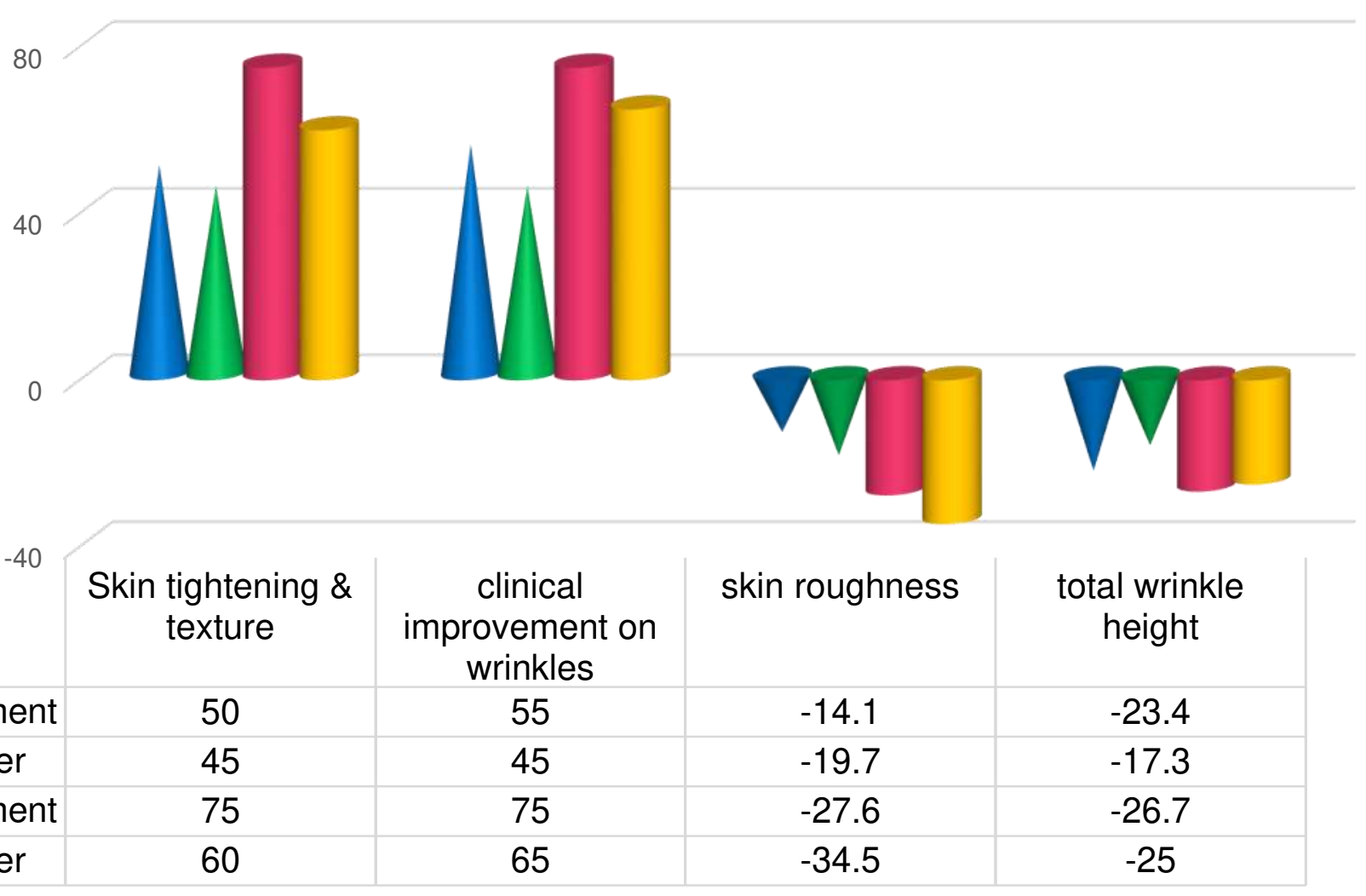

Quantitative evaluation of type VII collagen also revealed differences between F1 and F2.

The biosynthetic rate of elastin was evaluated by quantifying newly synthesized tropoelastin. Both formulations achieved good outcome on 4 weeks of treatment with high patient satisfaction confirmed by GAIS scale.

\section{Histological changes}

F2 - Total dermal elastin and tropoelastin

F1 - Total dermal elastin and tropoelastin

$$
\begin{aligned}
& \text { F2 - Collagen Type VII } \\
& \text { F1 - Collagen Type VII }
\end{aligned}
$$

F2 - Newly synthesized collagen

F1- Newly synthesized collagen

$$
\begin{aligned}
& \text { F2 - Collagen Type III } \\
& \text { F1 - Collagen Type III } \\
& \text { F2 - Collagen Type I } \\
& \text { F1 - Collagen Type I }
\end{aligned}
$$
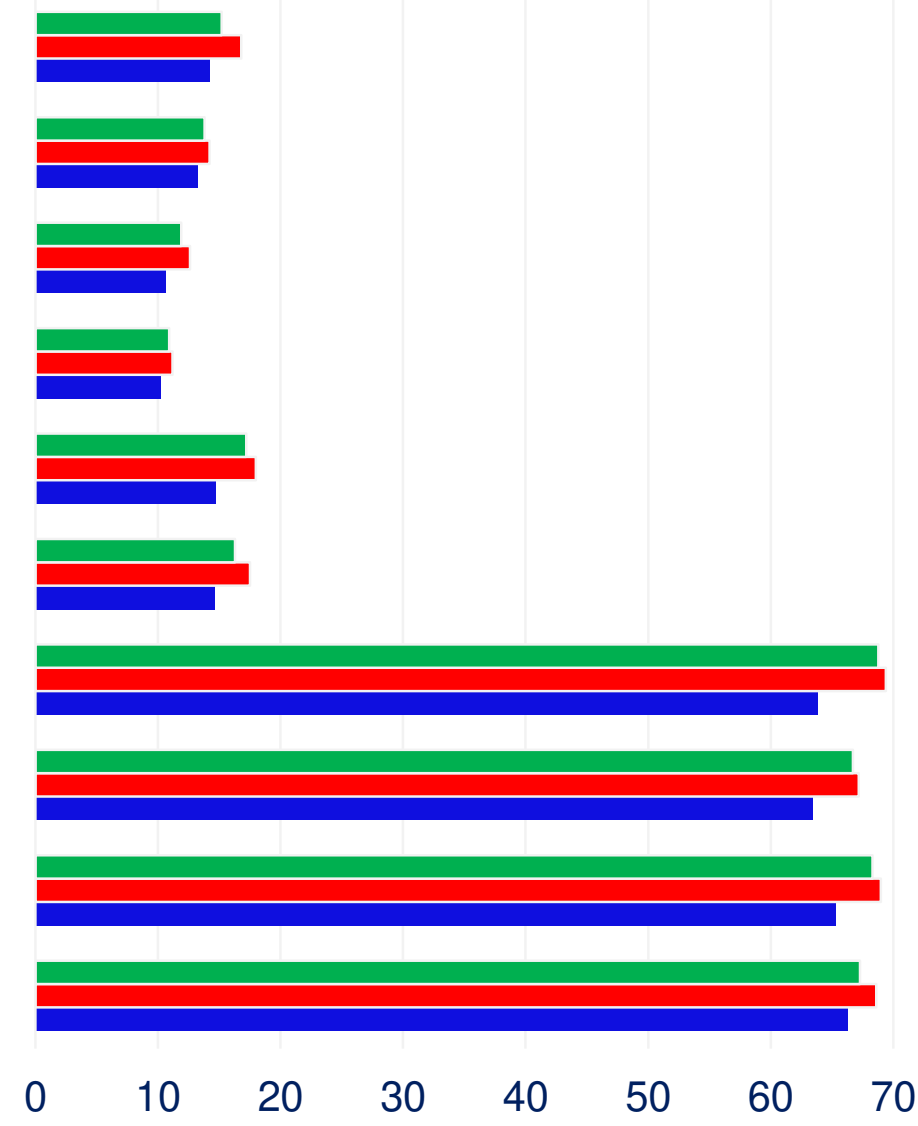

- 3 months after - end of study - Baseline

Histological changes (\%)

\begin{tabular}{|l|r|r|r|}
\hline & $\begin{array}{l}\text { Baselin } \\
\text { e }\end{array}$ & $\begin{array}{l}\text { End of } \\
\text { study }\end{array}$ & $\begin{array}{l}\text { 3 months } \\
\text { after }\end{array}$ \\
\hline F1 - Collagen Type I & 66.3 & 68.6 & 67.3 \\
\hline F2 - Collagen Type I & 65.3 & 69 & 68.3 \\
\hline F1 - Collagen Type III & 63.4 & 67.2 & 66.7 \\
\hline F2 - Collagen Type III & 63.8 & 69.4 & 68.8 \\
\hline $\begin{array}{l}\text { F1- Newly synthesized } \\
\text { collagen }\end{array}$ & 14.6 & 17.5 & 16.3 \\
\hline $\begin{array}{l}\text { F2 - Newly synthesized } \\
\text { collagen }\end{array}$ & 14.7 & 18 & 17.2 \\
\hline F1 - Collagen Type VII & 10.2 & 11.2 & 10.9 \\
\hline $\begin{array}{l}\text { F2 - Collagen Type VII } \\
\text { F1 - Total dermal elastin and } \\
\text { tropoelastin }\end{array}$ & 10.6 & 12.6 & 11.9 \\
\hline $\begin{array}{l}\text { F2 - Total dermal elastin and } \\
\text { tropoelastin }\end{array}$ & 13.2 & 14.2 & 13.8 \\
\hline
\end{tabular}

In conclusion, minimally invasive mesotherapy with F1 and F2 demonstrated effectiveness supported by instrumental and clinical evaluations. Obtained results confirmed F2 statistically considerable outcomes on treatment and prolonged effect compare to F1. Clinically F2 appeared visible on periorbital area smoothing numerous fine lines whereas $F 1$ revealed highly noticeable effect on forehead. In future clinical practice it is advisable to use both formulas on different areas in accordance to achieve maximum result. 